\title{
GORDOST U FRAZEOLOGIJI NEMAČKOG I SRPSKOG JEZIKA
}

U radu se analiziraju frazeologizmi nemačkog i srpskog jezika kojima se konceptualizuje gordost. Cilj rada je utvrđivanje strukture koncepta gordosti, te postulisanje kognitivnih mehanizama u pozadini frazeologizama i utvrđivanje sličnosti i razlika među ovim jezicima u načinu konceptualizacije gordosti. Istraživanje se vrši u okvirima kognitivne lingvistike, primenom konceptualne analize, a korpus je ekscerpiran iz odgovarajućih dvojezičnih i jednojezičnih onomasioloških i semasioloških rečnika.

Ključne reči: gordost, frazeologizmi, kontrastivna i konceptualna analiza, pojmovna metafora i metonimija, iskustveno znanje.

\section{UVOD}

Predmet rada je konceptualizacija gordosti u frazeologiji nemačkog i srpskog jezika, a istraživanje se vrši u teorijskim okvirima kognitivne lingvistike, odnosno frazeologije. Cilj rada je utvrđivanje strukture koncepta gordosti i postulisanje kognitivnih mehanizama $\mathrm{u}$ pozadini frazeologizama ${ }^{1}$ nemačkog $\mathrm{i}$ srpskog jezika u okviru koncepta gordosti. Korpus rada je leksikografskog tipa i ekscerpiran je iz dvojezičnih i jednojezičnih onomasioloških i semasioloških frazeoloških rečnika nemačkog i srpskog, odnosno srpskohrvatskog jezika². Primenjena metoda je kontrastivna i konceptualna analiza.

Gordost, lat. superbia, prema hrišćanskom shvatanju, jedan je od sedam smrtnih grehova ili jedna od osam strasti. Prema Svetom Jovanu Kasijanu, asketi iz 3, odnosno 4. veka, gordost je po vremenu i početku nastanka prva i najsvirepija strast koja napada savršene u trenutku kada dostignu gotovo vrhunac vrline (Kasijan

\footnotetext{
*mirjana.zarifovic@ff.uns.ac.rs

${ }^{1}$ Pod frazeologizmima podrazumevamo čvrste spojeve reči koji u rečenici i sistemu mogu da preuzmu funkciju i značenje pojedinačnih leksema (Palm 1997: 1), a odlikuju se polileksikalnošću, idiomatičnošću, ustaljenošću, leksikalizovanošću i reprodukovanjem.

${ }^{2} \mathrm{~S}$ obzirom na korišćene rečnike u nekim frazeologizmima javlja se ijekavica.
} 
2015: 251). Ta strast (ili greh) čini čoveka slepim za svaku pravednost, a iz njega progoni sve vrline, te je izvor svih drugih grehova. Prema Laršeu (2017), gordost može da ima dva oblika: gordost prema bližnjima i gordost prema Bogu ${ }^{3}$. U prvom obliku gordosti čovek sebe poredi sa drugima, smatra se uzvišenijim od ostalih, divi se sebi i udižući sebe ponižava bližnje - gleda ih sa visine, ne ceni druge, uveren je da je uvek u pravu, ne primećuje svoje mane, ne prihvata kritike, ne trpi autoritete. Naposletku, čovek sebe toliko uzdiže da postaje uobražen, nadmen i ohol (Larše 2017: 230-232). U Psihološkom rečniku oholost se definiše kao „precenjivanje sopstvenih vrednosti i moći, uz manje ili veće potcenjivanje drugih. Ako se javlja u okviru neke patologije, vezana je za megalomaniju ${ }^{4}$ [...]“ (Krstić 1988: 404). Rečnik Matice srpske definiše gordost na sledeći način: „stanje, osobina onoga koji je gord; oholost, ponositost", a pridev gord kao: ,a. ohol; nadmen; nepristupačan; ponosan“ (RMS 1967: 532). U radu se zbog navedenih stavova gordost posmatra kao hiperonim za nadmenost, uobraženost, prezir, nepoštovanje drugih i oholost, te se analiziraju frazeologizmi kojima se iskazuju ove osobine.

\section{STRUKTURA KONCEPTA}

U okviru kognitivne lingvistike konstruisanje značenja izjednačava se sa konceptualizacijom, a koncept je mentalni konstrukt koji čine načini kategorisanja iskustava i organizovane informacije koje posedujemo. Frazeologizmi na poseban način prikazuju predstave čoveka o samom sebi i svetu koji ga okružuje, ali omogućavaju samo „delimičan pristup konceptu odnosno čovekovoj konceptosferi““ (Štrbac 2018: 32). To znači da koncept verbalizovan frazeologizmima strukturišu samo određene komponente. Analizom korpusa utvrdili smo da je koncept gordosti strukturisan sledećim komponentama:

\footnotetext{
${ }^{3}$ Gordost prema Bogu manifestuje se kao odricanje od Boga, uzdanje isključivo u vlastitu snagu, a ne u Božiju pomoć, te je upravo taj oblik gordosti izazvao pad Satane i anđela koji su postali demoni (Larše 2017: 233). U radu će biti razmatran samo prvi oblik gordosti gordost prema bližnjima.

${ }^{4}$ „Megalomanija, manija veličine; ne podrazumeva obavezno maniju, čak je retko vezana za manična stanja, već je čine ideje o sopstvenoj veličini a u okviru ponašanja koje bi se moglo oceniti kao skoro normalno [...] Pritajeno, ili u nekom stepenu otvoreno, subjekt teži da sebe vidi ili prikaže kao „gospodara sveta“, koji je iznad svih u pogledu određenih dimenzija, ili na svim kriterijumima. [...]““ (Krstić 1988: 319, 319 f.).
} 
1. držanje tela subjekta gordosti,

2. način na koji subjekat gordosti sebe doživljava,

3. ponašanje/ postupci subjekta gordosti,

4. odnos subjekta gordosti prema drugim ljudima,

5. odnos okoline prema subjektu gordosti.

2.1. Držanje tela subjekta gordosti bihejvioralni je odgovor, odnosno fizička reprezentacija ove emocije koju subjekat nosi u sebi. Taj odgovor uglavnom podrazumeva visoko podignutu glavu i nos: die Nase in den Wolken haben - nosem parati nebo ${ }^{5}$; erhobenen Hauptes - uzdignute glave. Držanje tela može da se odnosi i na način na koji se subjekat gordosti kreće: herumstolzieren wie der Hahn auf dem Mist - šepuriti se kao petao na bunjištu ili na promene u konstituciji tela subjekta gordosti: sich aufblasen wie ein Frosch - naduti se kao žaba. Kao što se može primetiti, u oba slučaja reč je o poredbenim ${ }^{6}$ frazeologizmima sa zoonimnom komponentom.

2.2. Subjekat gordosti sebe doživljava ili tako što umišlja sopstvenu intelektualnu veličinu i čulne sposobnosti, kao u primeru: jemand meint, er hätte das Pulver erfunden; jemand meint, er höre das Gras wachsen; ili razlozi za umišljenost nisu jasno definisani iskazom: jemand denkt, dass sich alles um ihn dreht - misli neko da se oko njega vrti svet. Subjekat gordosti sebe smatra uzvišenim u odnosu na neke situacije: unter jemandes Würde sein - biti kome ispod časti.

2.3. Ponašanje i postupci subjekta gordosti ogledaju se u hvaljenju subjekta gordosti samog sebe: die Klappe aufreißen - hval'te me usta da vas ne poderem. Subjekat gordosti svojim ponašanjem može da zahteva da uvek bude tretiran na poseban način, jer smatra da je bolji od drugih, da zaslužuje više od drugih i shodno tome insistira da mu se ukaže posebna pažnja i čast: immer eine Extrawurst

${ }^{5}$ Kako se ne bi izašlo iz predviđenog obima rada, navodićemo samo najreprezentativnije primere za komponente, a kasnije i za kognitivne mehanizme.

${ }^{6}$ Većina autora na sličan način definiše poredbene ili komparativne frazeologizme. Prema Pilcu, reč je o frazeologizmima koji nadilaze ostale klase frazeologizama i koji uglavnom sadrže poredbenu partikulu wie ili als (u srpkom jeziku kao) (Pilz 1981: 83, 83 ff), dok Palmova dodaje da se, osim što komparativni frazeologizmi sadrže semantički odnos poređenja, taj odnos ostvaruje (i jasno je vidljiv) na samoj površini frazeologizma, za razliku od metafore koja se krije u drugim frazeologizmima (Palm 1997: 45). 
gebraten haben wollen - tražiti/ očekivati pečene ševe. Neretko se subjekat gordosti nameće drugima i bori se za vodeću poziciju (uveren da mu ona pripada): sich in den Vordergrund drängen (bez frazeološkog prevodnog ekvivalenta), te za glavnu reč: immer das große Wort führen - voditi glavnu reč. Ponašanje subjekta gordosti može da se poredi sa različitim osobama ili religijskim bićima: biti/ držati sel vladati se kao mali car; jemand benimmt sich wie der liebe Gott-ponaša se kao da je bog.

2.4. Frazeologizmima auf jemanden von oben herabschauen - gledati koga $s$ visoka; jemanden über die Schulter/die Achsel ansehen - gledati s visine iskazuje se način na koji subjekat gordosti posmatra druge ljude, poredi se i oseća se uzvišeno u odnosu na druge. Prezir prema drugima (zbog umišljene superiornosti) ogleda se u frazeologizmu jemand behandelt jemanden wie den letzten Dreck - ne bi netko o koga ni prljavu/ posranu nogu obrisao.

2.5. Najmanje je zabeleženih frazeologizama kojima se iskazuje stav okoline prema subjektu gordosti i tu je ili reč o frazeologizmima kojima se samo indirektno iskazuje stav prema subjektu gordosti: držati se/ vladati se kao mali car ili se direktno iskazuje uništavanje nečije gordosti: jemandes Stolz beugen - slomiti nečiju gordost.

\section{KONCEPTUALNA ANALIZA}

Konceptualna analiza pogodna je za izučavanje značenja apstraktne leksike. Prema Lejkofu (Lakoff 1987) i Kevečešu (Kövecses 1996), najproduktivniji kognitivni mehanizmi koji motivišu značenje frazeologizama su pojmovna metafora, pojmovna metonimija $\mathrm{i}$ iskustveno znanje. Pojmovna metafora predstavlja razumevanje apstraktnijeg pojma ili pojmovnog domena preko konkretnijeg pojma ili pojmovnog domena. Konkretniji domen naziva se izvornim i čulno je razumljiv, a njegova struktura preslikava se na apstraktniji ili ciljni domen. Princip prema kojem se preslikavanje vrši je jednosmeran, jer se ono uvek odvija od konkretnog ka apstraktnom (Klikovac 2004: 17). Lejkof i Džonson, začetnici teorije pojmovne metafore, razlikuju strukturne, orijentacione i ontološke metafore ${ }^{7}$

${ }^{7}$ Kod strukturnih metafora jedan pojam metaforički se strukturiše pomoću drugog, na primer: VREME JE NOVAC (Ovaj uređaj mi je uštedeo mnogo vremena). Orijentacione metafore zasnivaju se na našem prostornom iskustvu. Izvorni domeni su pojmovi kao što su gore-dole, napred-nazad, unutra-spolja itd, a primer je SREĆA JE GORE (Ta vest mi je podigla raspoloženje.). Kod ontoloških metafora aktivnosti, događaje, emocije itd. vidimo 
(Lakoff, Johnson 2007). Pojmovna metonimija je kognitivni proces u kojem jedan pojam ili entitet omogućava mentalni pristup drugom pojmu ili entitetu u okviru istog domena. Veza između pojmova ili entiteta zasniva se na bliskosti u okviru istog pojmovnog domena, za razliku od pojmovne metafore kod koje se veza zasniva na sličnosti između dva domena (Dragićević 2007: 161). Treći, veoma produktivni, pojmovni mehanizam koji motiviše značenja frazeologizama je iskustveno znanje (eng. coventional knowledge), pod kojim Kevečeš (Kövecses 1996) podrazumeva znanja u vezi sa nekim domenom koja su rasprostranjena $u$ određenoj kulturi. Međutim, ovi mehanizmi često ne deluju sami, već se međusobno prepliću ili proizilaze jedan iz drugog.

\subsection{GORDOST JE GORE ${ }^{8}$}

Orijentaciona metafora igra veoma značajnu ulogu u razumevanju moralnih kategorija kao što su dobro-loše, iskrenost, poštenje itd. i njihove suprotnosti (Kövecses 2010: 23; 40). Prema opštem shvatanju, dobre, pozitivne osobine, osećanja, pojmovi i entiteti orijentisani su ka gore ili se nalaze gore, a loše dole (Lakoff, Johnson 2007: 18). Rasulić (2003) smatra da je vertikalna orijentacija u prostoru veoma produktivan izvorni domen za konceptualizaciju apstraktnih pojava zbog čovekovog iskustva sa silom Zemljine teže i uspravnim položajem čovekovog tela. Na osnovu ljudskog iskustva zna se da je viši položaj povoljniji zbog bolje preglednosti, mogućnosti kretanja i delovanja, te taj položaj neretko podrazumeva fizičku snagu ,[...] a u fizičkoj borbi pobednik je gore, a poraženi dole, na osnovu čega se konceptualizuje opšti pojam moći.“ (Rasulić 2003: 242). Kako je gordost uverenost čoveka u sopstvenu superiornost nad drugim ljudima, metafora GORDOST JE GORE ${ }^{9}$ nalazi se u pozadini značajnog broja frazeologizama, na primer: auf jemanden von oben herabschauen - gledati koga $s$ visoka ${ }^{10}$. U

kao entitete ili supstance, na primer ČOVEKOV UNUTRAŠNJI SVET JE LOMLJV PREDMET (Njegovo samopouzdanje je veoma krhko; Slomila se pod naletom emocija.).

${ }^{8}$ Pojmovi i kognitivni mehanizmi predstavljeni su velikim slovima, kako je uobičajeno u kognitivnoligvističkim istraživanjima.

9 „Za ove metafore postoji jasna motivacija, jer se radi o našem mišljenju i osećanju da smo bolji, moćniji od drugih - mislimo da smo ,iznad' njih.“" (Broćić 2012: 132).

${ }^{10}$ Ovaj oblik gordosti strukturisan pojmovnom metaforom GORDOST JE GORE odgovara već pominjanom Laršeovom viđenju (2017: 230) da je prvi oblik gordosti onaj kada čovek sebe smatra uzvišenim u odnosu na druge ljude, kada traži nadmoć, ako je već i ne poseduje. Duboku ukorenjenost ove metafore vidimo i u rečima pomenutog autora: „Gordost se u 
frazeologizmu die Nase in den Wolken haben - nosem parati nebo zapažamo umrežavanje metafore GORDOST JE GORE (što se ogleda u upotrebi konstituenta Wolken / nebo) i metonimije tipa efekat emocije za emociju (Kövecses 2008: 131). Visoko podignuta glava ili nos, najistaknutiji deo glave, bihejvioralni je odgovor na osećaj velikog ponosa, naročito gordosti. Subjekat gordosti povija ramena nazad, ispravlja leđa, istura grudi napred (Kövecses 2008: 133), visoko podiže glavu, a stav tela iskazan je nosom koji dodiruje ili para ${ }^{11}$ nebo. U primeru die Nase hochtragen u srpskom jeziku zabeležen je prevodni ekvivalent u kojem se preslikavanje ne vrši iz ljudskog domena, već iz životinjskog domena na ljudski: dići/ podići rep. Ovo preslikavanje verovatno se odvija preko slike mačke kao životinje koja se ponosno šeta visoko podignutog repa. Umrežavanje metafore GORDOST JE GORE i metonimije PODIGNUT NOS/ GLAVA ZA GORDOST zapaža se i u frazeološkim parovima erhobenen Hauptes - uzdignute glave i jemanden über die Schulter/ die Achsel ansehen - gledati s visine, a u drugom navedenom paru u nemačkom jeziku se visina iskazuje pogledom iznad ramena, tj. pogled iznad ramena stoji za visinu sa koje subjekat gordosti posmatra druge ljude. U ovom primeru u osnovi imamo metonimiju VISINA ZA VISINU GLAVE, a ona se zasniva na metonimiji GLAVA ZA OČI, jer se u frazeologizmu to doslovno ne ističe, ali je jasno da se gleda očima.

\subsection{GORDOST JE DRUŠTVENA SUPERIORNOST}

RMS superiornost definiše kao „nadmoć, preimućstvo“, odnosno, superioran je onaj ,[...] koji drži da je iznad ostalih, koji se oseća nadmoćnim u odnosu na druge prema kojima se određuje“ (RMS 2011: 1266), te nije slučajnost da se u objašnjenju ovog pojma upotrebljava prefiks nad- - time se ističe doživljaj subjekta gordosti da je iznad drugih ljudi, tj. ova metafora je varijanta metafore GORDOST JE GORE. Strukturna metafora GORDOST JE DRUŠTVENA SUPERIORNOST u pozadini je frazeologizama kod kojih se u leksičkom sastavu očituje da je gordost uobražavanje veličine ili nadmoći: sich wichtig machen -

\footnotetext{
svakom slučaju zasniva na tome da se uzdigne, [...]. [...] Uzdižući se, ... [...].[...] Čovek zbog gordosti oseća potrebu da se poredi s drugima, da uspostavlja hijerarhiju [...]“ (2017: 230, 230ff).

${ }^{11}$ Upravo zbog slike paranja ne sme se zanemariti da se u pozadini ovog frazeologizma nalazi i metafora GORDOST JE OŠTAR PREDMET, koja bi bila podmetafora šire metafore GORDOST JE RAZORNA SILA.
} 
praviti se važan; sie meint, wunders, wer sie sei - misli da je bog zna ko. Za frazeologizme nemačkog jezika bez prevodnog ekvivalenta na srpski jezik mogu se postulisati podmetafore: immer wieder etwas Besonderes sein wollen (GORDOST JE POSEBNOST/ ŽELJA ZA POSEBNOŠĆU - posebnost u društvu izdvaja, uzdiže čoveka iznad ostalih); ein kleiner Gernegroß sein (GORDOST JE HVALJENJE SEBE - uverenošću u svoju superiornost subjekat gordosti smatra da poseduje najbolje osobine); sich ein Ansehen geben (GORDOST JE ŽELJA ZA POŠTOVANJEM - društvena superiornost bi trebalo da zaslužuje poštovanje ljudi); den großen Herrn/ die feine Dame spielen i groß tun mit etwas (GORDOST JE VELIČINA/ FINOĆA - superiorno, tj. nadmoćno je veliko i fino); sich in den Vordergrund drängen (GORDOST JE NAPRED - društveno superiorne osobe trebalo bi da imaju lidersku poziciju u društvu); kao i za frazeologizam srpskog jezika biti/ držati se/ vladati se kao mali car. Ovaj frazeologizam Gordana Štrbac pojašnjava (2018: 182): ,[...] frazeološko značenje motivisano je implicitnim semama iz semantičkog potencijala lekseme car - car je nosilac najviše vladarske titule, kojem se stoga mogu pripisati oholost i gordost". Zanimljivo je to što se subjekat gordosti vidi kao „mali“ car, te je implicitno iskazan stav okoline prema osobi koja sebe smatra društveno superiornom - okolina sa ironijom posmatra takvu osobu i, za razliku od slike koju subjekat gordosti ima o svojoj veličini, okolina ima dijametralno suprotnu predstavu. U okviru metafore GORDOST JE DRUŠTVENA SUPERIORNOST uočavamo frazeološki par jemandem wird kein Zacken aus der Krone fallen/ jemandem fällt kein Stein/ keine Perle aus der Krone - neće kome pasti kruna s glave koji je nastao na osnovu iskustvenog znanja o kruni. Kruna, odnosno ukrasi na kruni simbolizuju pripadanje određenom društvenom staležu i predstavljaju društvenu (nad)moć, a komponenta fallen/ pasti implicira orijentacionu metaforu GORDOST JE GORE (odnosno: ODSUSTVO GORDOSTI JE DOLE). Iskustveno motivisan je i nemački frazeologizam auf hohem Roß sitzen - gledati s visine na druge. U pozadini frazeologizma srpskog jezika očigledno je da je orijentaciona metafora GORDOST JE GORE, dok se u nemačkom jeziku, iako na osnovu leksičkog sastava neprozirno, osim prostorne metafore (koja se očituje u leksemi hoch), krije i metafora GORDOST JE DRUŠTVENA SUPERIORNOST. U vreme nastanka frazeologizma, u 16. veku, imenica Roß korišćena je za razlikovanje ratnog, borbenog konja $(R o \beta)$ od konja korišćenog za vuču (Pferd) (www.redensarten-index.de). Samim tim što je konj koji je korišćen u bitkama i ratnim pohodima smatran elitnim, uzvišenim i superiornijim u odnosu na druge konje, i vlasnik konja smatran je pripadnikom elite, te se borbeni konj $(R o \beta)$ može smatrati simbolom. 
U frazeologizmima nemačkog jezika (bez prevodnih ekvivalenata na srpski jezik) uočavamo da subjekat gordosti uobražava da poseduje intelektualnu nadmoć (jemand meint, er hätte das Pulver erfunden; der meint, er hätte ein Patent drauf; jemand meint, er höre das Gras wachsen itd.). Na pojmovnoj metafori društvene superiornosti, odnosno, podmetafori GORDOST JE PRAVO ODLUČIVANJA zasnovani su i frazeologizmi u kojima se ta superiornost iskazuje pravom na donošenje odluke, tj. kazivanja poslednje (odlučujuće) reči: er muss immer das letzte Wort haben - njegova je uvek poslednja; immer das große Wort führen voditi glavnu reč; gro $\beta$ daherreden (bez prevoda na srpski jezik); immer Recht behalten wollen (isto). Gordost se kao društvena superiornost manifestuje i kao osećaj da je subjekat gordosti uzvišen u odnosu na druge ljude, te nekog ili nešto potcenjuje: unter jemandes Würde sein - biti kome ispod časti; sich über etwas/ jemanden erhaben fühlen (bez prevodnog ekvivalenta). U ovim frazeologizmima uočavamo preplitanje metafora GORDOST JE GORE i GORDOST JE DRUŠTVENA SUPERIORNOST, te se potvrđuje teološko shvatanje da gordost nagna čoveka na poređenje sa drugima, na unižavanje drugih i uzdizanje sebe (Larše 2017: 231). Ista motivaciona baza je i u frazeološkom paru jemand behandelt jemanden wie Luft/ den letzten Dreck - ne bi netko o koga ni prljavu/ posranu nogu obrisao.

\subsection{GORDOST JE ŽIVO BIĆE/ ŽIVOTINJA/ ODREĐENA NACIONALNOST}

Frazeologizmi zasnovani na ovoj metafori mahom spadaju u grupu poredbenih frazeologizama. U nemačkom jeziku beleže se frazeologizmi stolz wie ein Pfau; stolz wie ein Hahn i stolz wie ein Adler sa istim frazeološkim parnjakom u srpskom jeziku - gord kao paun. Paun (nem. Pfau) je prema Bidermanu kitnjasta životinja koja uglavnom ima pozitivno značenje, ali joj se u ranohrišćanskom „Fiziologu“ dodaje i negativna konotacija - jer paun rado stresa perje, šepuri se i nadmeno gleda svet oko sebe, zbog čega ,[...] simbolizuje sujetu, luksuz i nadmenost (superbia)“ (Biderman 2004: 291, 292). Životinja koja, osim niza pozitivnih osobina, ,zbog pogleda uprtog u daljinu, koji izgleda kao da ignoriše stvari oko sebe“" (Biderman 2004: 270), simbolizuje gordost je orao (nem. Adler). Subjekat gordosti se u nemačkom jeziku poredi i sa petlom (nem. Hahn) zbog njegove osobine da ide ispred kokošaka i zbog načina na koji (samouvereno) šeta (www.redensarten-index.de). Ova životinja posebno voli da se šeta $i$ ističe na uzdignutim mestima, te je ova osobina (gordog) petla sačuvana u frazeologizmu herumstolzieren wie der Hahn auf dem Mist - šepuriti se kao petao na bunjištu. U frazeologizmu oba jezika životinja se pravi važna, svojim hodom odaje sliku koju 
ima o sebi, a zapravo, nalazi se u prljavštini, na đubrištu, odnosno bunjištu, u čemu se ogleda moralni stav okoline prema subjektu gordosti. Životinja sa kojom se subjekat gordosti poredi je i fijakerski konj, ukrašena, nagizdana životinja koja ponosno korača (a zapravo je vezana i sputana): stolz wie ein Kutschenpferd - gord kao fijakerski konj. Konj u ovoj slici verovatno nije izabran samo zbog ukrasa koje mu čovek stavlja kada ga preže u fijaker, već i zbog stava tela, visoko podignute glave i isturenih grudi, ponovo bihejvioralnog odgovora (čoveka) na osećaj velikog ponosa i gordosti. Životinja sa kojom se zbog uvećanja tela poredi subjekat gordosti je i žaba: sich aufblasen wie ein Frosch - naduti se kao žaba. Frazeologizam potiče iz Ezopove basne o žabi i volu, u kojoj je žaba želela da bude veća od vola i pokušavala je da naduva mehur za pojačavanje zvuka kako bi prestigla vola $u$ veličini. Toliko je pokušavala da se naduva i uveća, dok nije pukla (www.redensarten-index.de), te vidimo da je ovaj frazeologizam iskustveno motivisan (zbog iskustva sa ponašanjem žaba), odnosno intertekstualno, ako znamo etimologiju frazeologizma (Dobrovol'skij, Piirainen 2009: 32).

Osim životinja kao objekat poređenja u nemačkom jeziku koriste se i ljudi: stolz wie ein Spanier i stolz wie Oskar sein (oba bez frazeološkog prevodnog ekvivalenta). Prvi primer je metonimijski zasnovan, po obrascu pars pro toto, gde se uzima nacionalni ponos (nekih) Španaca da bi se predstavio nacionalni ponos celog naroda. U drugom primeru reč je o ustaljenoj igri rečima kao posebnom obliku metaforičke motivacije (Dobrovol'skij, Piirainen 2009: 29). Ovakvi frazeologizmi se ne mogu interpretirati neposredno na metaforičnoj bazi, već samo na osnovu igre rečima koja počiva na fonetskim elementima. Ime Oskar asocira na reč Ochse (= vo), a poreklo vodi od keltskog oss (= jelen) i staroirskog car (= mio). Ime Oskar je u 18. veku postalo veoma popularno u Nemačkoj zahvaljujući književnoj prevari i oduševljenju Makfersonovim delom Ossian (Ossian se smatra deminutivom imena Oskar). Stoga je ono upotrebljeno prilikom etimološkog reinterpretiranja izraza na jidišu Ossoker, što znači „drzak momak“ (www.redensarten-index.de), a sadržano je u nemačkom frazeologizmu frech wie Oskar. Ovo ime je po analogiji upotrebljeno i za druga poređenja, odnosno iskazivanja negativnih osobina, kao što je to slučaj u primeru stolz wie Oskar sein.

\subsection{GORDOST JE FIZIČKA/ PRIRODNA SILA}

U pozadini frazeologizma jemand denkt, dass sich alles um ihn dreht misli neko da se oko njega vrti svet leži pojmovna metafora GORDOST JE FIZIČKA SILA, odnosno podmetafora GORDOST JE SUNCE. Frazeološki par zasnovan je na konvencionalnom znanju da se oko Sunca okreće i naša planeta (naš 
svet), a da je Sunce, ,izvor života“. I u ovom frazeologizmu, kao i u drugim frazeologizmima kojima se u oba jezika iskazuje gordost, ne sme se izgubiti iz vida da je gordost, zapravo, viđenje sebe, doživljaj samog sebe. Ista metafora motiviše frazeologizam vor Stolz (fast) platzen - pući od gordosti, pri čemu je gordost razorna, eksplozivna sila koja nastaje kada se neka posuda prepuni (gordošću), te frazeologizam počiva na iskustvenom znanju SADRŽATELJ KOJI SE PREPUNI PUKNE. Sila koja je usredsređena na samouništenje leži u pozadini frazeologizma sich in die Brust werfen - busati se u grudi. Grudi ovde predstavljaju bihejvioralni odgovor subjekta gordosti na osećaj (prevelikog) ponosa (gordosti), koji i Kevečeš potvrđuje da je zasnovan metonimijski efektom emocije za emociju i navodi primer „chest out for pride“ (Kövecses 2008: 133). U nemačkom i srpskom jeziku ne samo da je ceo grudni koš isturen i da subjekat gordosti pokušava da uveća i svoju fizičku veličinu (www.redensarten-index.de), već se subjekat gordosti, u želji da svima obznani tu ponositost sobom, udara u grudi, dakle, autodesktruktivan je. Očita je autodestruktivnost i u primeru die Klappe aufreißen - hval'te me usta da vas ne poderem $^{12}$, pri čemu je u srpskom jeziku sadržana i pretnja (da vas ne poderem), dok se u nemačkom jeziku usta toliko jako otvaraju (da bi hvalila subjekat, u ovom slučaju bolje rečeno objekat gordosti, tj. hvale), da se cepaju.

\subsection{GORDOST JE OTEŽANA VIDLJIVOST/ ATAK NA OČI/ NEMOGUĆNOST VIDA}

Za osobu koja voli da preuveličava stvari, ali i da se hvali, u nemačkom jeziku koristi se frazeologizam Schaum schlagen koji je motivisan slikom zapenjene vode $u$ kojoj se od pene ne vidi prljavština u vodi (www.redensarten-index.de), te vidimo da iskustveno znanje motiviše ovaj frazeologizam, u pozadini kojeg je metafora GORDOST JE OTEŽANA VIDLJIVOST. U srpskom jeziku se kao ekvivalent za ovaj frazeologizam u rečnicima navodi frazeologizam bacati prašinu $u$ oči, u osnovi kojeg je metafora GORDOST JE ATAK NA OČI. Ovaj frazeologizam u srpskom jeziku možemo samo pod posebnim okolnostima posmatrati kao prevodni ekvivalent za frazeologizam nemačkog jezika, jer je

${ }^{12}$ Ovaj frazeološki par nije prototipičan za koncept gordosti, jer se nalazi na njegovoj periferiji. On se nalazi u centru koncepta hvalisavosti, ali kako koncepti nisu jasno omeđeni, često dolazi i do preplitanja koncepata, posebno perifernih delova koncepata. Tako se ovaj frazeološki par može posmatrati kao netipični predstavnik koncepta gordosti, jer je hvalisanje i potreba za verbalnim uzdizanjem samog sebe česta odlika gordih osoba. 
rečničko značenje frazeologizma srpskog jezika „obmanuti/ obmanjivati nekoga, prevariti/ varati nekoga, dovesti/ dovoditi nekoga u zabludu“"(Otašević 2012: 715). Ukoliko subjekat gordosti sebe prikazuje na drugačiji način od onoga što on zapravo jeste i time obmanjuje druge ljude, ovaj frazeologizam možemo svrstati u koncept gordosti. U takvom shvatanju i počivajući na pojmovnoj metafori GORDOST JE ATAK NA OČI gorda osoba zaslepljuje druge (baca prašinu u oči), kako oni ne bi mogli da vide pravo lice subjekta gordosti, već sliku o sebi koju ta osoba (ima i) prikazuje. Gordost kao nemogućnost subjekta gordosti da vidi druge (GORDOST JE NEMOGUĆNOST VIDA) iskazana je frazeologizmom jemanden wie Luft behandeln (doslovno: „tretirati nekog kao vazduh“) za koji u srpskom jeziku ne postoji frazeološki ekvivalent. Ovaj frazeologizam temelji se na iskustvenom znanju - vazduh ( $\mathrm{Luft}$ ) je nevidljiv, što je poznato svakom čoveku; subjekat gordosti ophodi se prema drugima kao da su oni nevidljivi, prozirni, a ako se ne vide, nisu vredni ili ni ne postoje (za subjekta gordosti).

\subsection{GORDOST JE SITOST}

Frazeologizam jemand glaubt, die Weisheit mit Löffeln gegessen zu habenmisli neko da je svu mudrost kašikom pojeo u osnovi ima predstavu o gordosti kao vidu sitosti koja nastaje konzumiranjem mudrosti ili pameti, a da bi slika bila očiglednija i vernija, ta hrana se konzumira kašikom. Gordost je nedostatak duševne hrane (www.redensarten-index.de), za koju subjekat gordosti smatra da se može nadomestiti na najjednostavniji način - jelom, dakle, preko usta. Frazeologizam motivisan hranom i ispunjenošću usta hranom je den Mund vollnehmen - puna mu usta sebe. Iako hrana nije izričito navedena u ovom primeru, može se pretpostaviti da se na nju misli, jer su usta ispunjena sobom, obožavanjem samoga sebe i potrebom za hvaljenjem sebe. Kako ovde usta predstavljaju ispunjenost celoga tela doživljajem sebe, na delu je metonimijska motivacija. Ispoljavanje gordosti kao želje za posebnošću koja se reflektuje putem hrane primetno je u frazeologizmu immer eine Extrawurst gebraten haben wollen - tražiti, očekivati pečene ševe, gde se u nemačkom jeziku očekuje posebna kobasica $^{13}$, a u srpskom jeziku ševe predstavljaju, takođe, posebnost, retkost, s obzirom na njihovo prirodno stanište.

\footnotetext{
${ }^{13}$ Kobasice su u srednjem veku predstavljale delikates za siromašne ljude, pa bi se još „posebna kobasica“- Extrawurst mogla posmatrati kao augmentativ.
} 


\subsection{GORDOST JE LOMLJIV PREDMET}

Frazeologizam koji je zabeležen u oba jezika ne oslikava gordost kao osobinu, već naprotiv, uništenje gordosti: jemandes Stolz beugen - slomiti nečiju gordost. U nemačkom jeziku gordost se savija (beugen), u srpskom lomi, ali je zajednička slika da je gordost čvrst predmet koji se može i drugačije oblikovati ili čak i slomiti. Način na koji se lomljenje tog predmeta (gordosti) izvodi nije iskazan, te možemo da pretpostavimo da je reč o verbalnom savijanju ili lomljenju nečije gordosti. U nemačkom jeziku beležimo varijantu ovog frazeologizma koja je bliži ekvivalent frazeologizmu srpskog jezika: jemandes Stolz (mit Gewalt) (nicht) brechen können i realizaciju u kontekstu: ,...Ach, der Mann weiß natürlich genauso gut wie wir - nein besser! -,daß er falsch gehandelt hat. Aber er hat nun einmal seinen Stolz, und mit Gewalt werden wir diesen Stolz auch nicht brechen.[...] ${ }^{\text {(14 }}$ (Schemann 2011: 808). Iz ovoga možemo da utvrdimo da je lomljenje gordosti, ujedno, priznavanje subjekta gordosti da je pogrešio, da nije u pravu i da treba da posluša druge, dakle, da deluje suprotno od onoga na šta ga gordost inače nagna.

\section{ZAKLJUČAK}

U radu su analizirani frazeologizmi nemačkog i srpskog jezika kojima je oslikan koncept gordosti. Analizirani korpus čini 56 frazeologizama nemačkog jezika i njihovi prevodni ekvivalenti na srpskom jeziku, pri čemu za čak 19 frazeologizama nemačkog jezika nije utvđen leksikalizovan frazeološki prevodni ekvivalent. Ipak, u fokusu nije kvantitativna, već kvalitativna komponenta korpusa, jer je cilj bio utvrđivanje strukturisanosti koncepta i postulisanje kognitivnih mehanizama koji motivišu frazeologizme oba jezika, te uočavanje sličnosti i razlika među njima. U radu su navođeni primeri frazeologizama za koje smo smatrali da su najreprezentativniji predstavnici uočene komponente ili pojmovnog mehanizma. Kontrastivnom i konceptualnom analizom utvrdili smo da iste komponente strukturišu koncept gordosti, s tim da je prilikom analize bilo više zabeleženih primera frazeologizama nemačkog jezika nego srpskog. Ovakvo stanje svakako ne daje za pravo da iznesemo pretpostavku da je nemački jezik bogatiji frazeologizmima, već to možemo pripisati činjenici da je nemački jezik bogatiji frazeološkim leksikonima od srpskog jezika. Prilikom postulisanja kognitivnih

\footnotetext{
${ }^{14}$ Prevod: ,... Ah, naravno da taj čovek kao i mi zna - ne, zna i bolje od nas! da je pogrešio. Ali on je gord i ni silom nećemo slomiti tu gordost [...]“.
} 
mehanizama utvrđena je velika sličnost u konceptualizaciji gordosti u nemačkom i srpskom jeziku, te zapažamo iste kognitivne mehanizme u pozadini frazeoloških parova. Najfrekventniji kognitivni mehanizam u oba jezika je pojmovna metafora, često umrežena sa drugom metaforom ili metonimijom, a najzastupljenija je metafora GORDOST JE DRUŠTVENA SUPERIORNOST. Upravo u okviru te metafore očituju se razlike u podmetaforama koje su postulisane većinom za frazeologizme nemačkog jezika (jer su brojniji u analiziranom korpusu, te ne iznenađuje veća diferenciranost kognitivnih mehanizama $u$ pozadini frazeologizama). Retki su primeri u kojima frazeološki parovi počivaju na različitim metaforama, kao što su to frazeologizmi auf hohem Roß sitzen (GORDOST JE DRUŠTVENA SUPERIORNOST) - gledati s visine na druge (GORDOST JE GORE). Ipak, ovakve razlike ne možemo smatrati krucijalnim da bismo zaključili da se u ovim jezicima na drugačije načine konceptualizuje gordost, jer je društvena superiornost izdvojenost društvenog sloja $k a$ gore, dakle, uočavamo bliskost izvornih domena. Pripadanje istom domenu uz manje razlike u nijansiranju metafora uočili smo i u okviru pojmovne metafore GORDOST JE OTEŽANA VIDLJIVOST/ ATAK NA OČI/ NEMOGUĆNOST VIDA. U srpskom jeziku ne beležimo primere poređenja subjekta gordosti sa pripadnikom određenog naroda ili ličnim imenom osobe, dok se takvi primeri beleže u nemačkom jeziku.

\section{Mirjana Zarifović Grković}

\section{PRIDE IN THE PHRASEOLOGY OF THE GERMAN AND SERBIAN LANGUAGE}

\section{Summary}

This paper deals with idioms in German and Serbian that conceptualize pride (superbia). The aim of the paper is to determine the structure of the concept pride in both languages and to postulate cognitive mechanisms. The analysis shows that idioms in both languages mark the same aspects of the concept pride: body posture of a proud person, the way the subject of pride perceives himself/herself, the way a proud person acts, a proud person's attitude to other people and the attitude of others towards a proud person. The cognitive mechanisms that motivate idioms of both languages show great similarities, and minor differences are observed in some of the sub-metaphors. The cognitive mechanisms that provide motivation for idoms of both languages are metaphor, metonymy and conventional knowledge, as it was expected, since the paper relies on the tradition of Lakoff (1987) and Kövecses (1996).

Key words: pride, idoms, contrastive conceptual analysis, conceptual metahor and metonymy, conventional knowledge. 


\section{LITERATURA}

Biderman, H. (2004). Rečnik simbola. Beograd: Plato.

Broćić, A. (2012). O konceptualizaciji pojmova ponos, gordost, oholost i nadmenost u srpskom jeziku. U: Ivić, P. (ured.). Zbornik Matice srpske za filologiju i lingvistiku. Knj. 55, sv. 2. Novi Sad: Matica srpska. 119-140. (štampano ćirilicom).

Dobrovol'skij, D. -Piirainen, E. (2009). Zur Theorie der Phraseologie. Kognitive und kulturelle Aspekte. Tübingen: Stauffenburg Verlag.

Dragićević, R. (2007). Leksikologija srpskog jezika. Beograd: Zavod za udžbenike. (štampano ćirilicom).

Kasijan, J. (2015). Borba sa osam glavnih strasti. U: Srbulj, J. (prir.). Dobrotoljublje. Šabac: Pravoslavac. 161-285. (štampano ćirilicom).

Klikovac, D. (2004). Metafore u mišljenju i jeziku. Beograd: Biblioteka XX vek.

Kövecses, Z. (2008). The Conceptual Structure of Happiness. In: Tissari, H. -Pessi,

A. B. -Salmela, M. (edts.). Happiness: Cognition, Experience, Language. Collegium. Studies across disciplines in the humanities and social sciences. Volume 3. Helsinki: Helsinki Collegium for Advanced Studies. 131-143.

Kövecses, Z. (2010). Metaphor. New York: Oxford University Press.

Kövecses, Z. -Szabo, P. (1996). Idioms: A View from Cognitive Semantics. In: Applied Linguistics, Volume 17 Issue. 326-355.

Krstić, D. (1988). Psihološki rečnik. Beograd: Izdavačka radna organizacija „Vuk Karadžić“.

Lakoff, G. (1987). Women, Fire and Dangerous Things. What Categories Reveal about the Mind. Chicago: The University of Chicago Press.

Lakoff, G. -Johnson, M. (2007). Leben in Metaphern. Heidelberg: Carl-Auer Verlag.

Larše, Ž-K. (2017). Lečenje duhovnih bolesti. Niš: Međunarodni centar za pravoslavne studije. Beograd: JP Službeni glasnik. (štampano ćirilicom).

Palm, Ch. (1997). Phraseologie. Eine Einführung. Tübingen: Gunter Narr Verlag.

Pilz, K. D. (1981). Phraseologie. Redensartenforschung. Stuttgart: Metzlersche Verlagsbuchhandlung.

Rasulić, K. (2003). Konceptualizacija društva pomoću vertikalne dimenzije. U: Klikovac, D. -Rasulić, K. (ured.). Jezik, društvo, saznanje: profesoru Ranku Bugarskom od njegovih studenata. Beograd: Filološki fakultet. 239254.

Stevanović, M. i dr. (1967). Rečnik srpskohrvatskoga književnog jezika. Novi Sad: Matica srpska. (štampano ćirilicom). 
Štrbac, G. (2018). Frazeologija o čoveku i čovek u frazeologiji. Novi Sad: Filozofski fakultet. (štampano ćirilicom).

Vujanić, M. - Gortan-Premk, D. -Dešić, M. -Dragićević, R. -Nikolić, M. -Nogo, Lj. Pavković, V. -Ramić, N. -Stijović, R. -Radošević-Tešić, M. -Fekete, E. (2011). Rečnik srpskoga jezika. Novi Sad: Matica srpska.

\section{IZVORI}

Dudenredaktion (Hrsg.) (2002). Duden. Redewendungen. Wörterbuch der deutschen Idiomatik. Mannheim, Leipzig, Wien, Zürich: Duden Verlag.

Krüger-Lorenzen, K. (1998). Deutsche Redensarten und was dahinter steckt. München: Wilhelm Heyne Verlag.

Matešić, J. (1982). Frazeološki rječnik hrvatskoga ili srpskog jezika. Zagreb: Školska knjiga.

Matešić, J. (1988). Hrvatsko-njemački frazeološki rječnik. Zagreb: Nakladni zavod Matice hrvatske.

Mrazović, P. -Primorac, R. (1981). Nemačko-srpskohrvatski frazeološki rečnik. Beograd: Narodna knjiga.

Otašević, Đ. (2012). Frazeološki rečnik srpskog jezika. Novi Sad: Prometej. (štampano ćirilicom).

Petronijević, B. (2007). Srpsko-nemački prevodni frazeološki rečnik. Beograd: Jasen.

Röhrich, L. (2004). Lexikon der sprichwörtlichen Redensarten. Freiburg: Herder.

Schemann, H. (1992). Synonymwörterbuch der deutschen Redensarten. Stuttgart, Dresden: Klett.

Schemann, H. (2011). Deutsche Idiomatik. Wörterbuch der deutschen Redewendungen im Kontext. Berlin, Boston: Walter de Gruyter.

Weinberger, H. (2012). Kroatisch/Serbisch-Deutsches phraseologisches Wörterbuch, angeordnet nach semantischen Gruppen. Wien: Facultas Verlags- und Buchhandels GmbH.

www.redensarten-index.de (poslednji put pristupljeno 19.3.2020). 
